\title{
Combined Ventilation of Two Subjects with a Single Mechanical Ventilator Using a New Medical Device: An In Vitro Study
}

\author{
Ignacio Lugones $\mathbb{( D},{ }^{1}$ Matías Ramos $\mathbb{D},{ }^{2}$ María Fernanda Biancolini $\mathbb{D}{ }^{3}$, \\ and Roberto Orofino Giambastiani $\mathbb{D i D}^{4}$ \\ ${ }^{1}$ Cardiac Surgery Unit, Children's General Hospital "Dr. Pedro de Elizalde”, Buenos Aires, Argentina \\ ${ }^{2}$ Department of Anesthesiology, Hospital de Clínicas "José de San Martín", Buenos Aires, Argentina \\ ${ }^{3}$ Department of Cardiology, Children's General Hospital "Dr. Pedro de Elizalde", Buenos Aires, Argentina \\ ${ }^{4}$ Department of Anesthesiology, Children's General Hospital "Dr. Pedro de Elizalde”, Buenos Aires, Argentina
}

Correspondence should be addressed to Ignacio Lugones; cardiocongenitas@gmail.com

Received 30 December 2020; Revised 31 January 2021; Accepted 9 February 2021; Published 19 February 2021

Academic Editor: Ferenc Petak

Copyright (c) 2021 Ignacio Lugones et al. This is an open access article distributed under the Creative Commons Attribution License, which permits unrestricted use, distribution, and reproduction in any medium, provided the original work is properly cited.

\begin{abstract}
Introduction. The SARS-CoV-2 pandemic has created a sudden lack of ventilators. DuplicAR ${ }^{\circledR}$ is a novel device that allows simultaneous and independent ventilation of two subjects with a single ventilator. The aims of this study are (a) to determine the efficacy of DuplicAR ${ }^{\circledR}$ to independently regulate the peak and positive-end expiratory pressures in each subject, both under pressure-controlled ventilation and volume-controlled ventilation and (b) to determine the ventilation mode in which DuplicAR ${ }^{\circledR}$ presents the best performance and safety. Materials and Methods. Two test lungs are connected to a single ventilator using DuplicAR ${ }^{\circledR}$. Three experimental stages are established: (1) two identical subjects, (2) two subjects with the same weight but different lung compliance, and (3) two subjects with different weights and lung compliances. In each stage, the test lungs are ventilated in two ventilation modes. The positive-end expiratory pressure requirements are increased successively in one of the subjects. The goal is to achieve a tidal volume of $7 \mathrm{ml} / \mathrm{kg}$ for each subject in all different stages through manipulation of the ventilator and the DuplicAR ${ }^{\circledR}$ controllers. Results. DuplicAR ${ }^{\circledR}$ allows adequate ventilation of two subjects with different weights and/or lung compliances and/or PEEP requirements. This is achieved by adjusting the total tidal volume for both subjects (in volume-controlled ventilation) or the highest peak pressure needed (in pressure-controlled ventilation) along with the basal positive-end expiratory pressure on the ventilator and simultaneously manipulating the DuplicAR ${ }^{\circledR}$ controllers to decrease the tidal volume or the peak pressure in the subject that needs less and/or to increase the positive-end expiratory pressure in the subject that needs more. While ventilatory goals can be achieved in any of the ventilation modes, DuplicAR ${ }^{\circledR}$ performs better in pressure-controlled ventilation, as changes experienced in the variables of one subject do not modify the other one. Conclusions. Duplic $A R^{\circledR}$ is an effective tool to manage the peak inspiratory pressure and the positive-end expiratory pressure independently in two subjects connected to a single ventilator. The driving pressure can be adjusted to meet the requirements of subjects with different weights and lung compliances. Pressure-controlled ventilation has advantages over volume-controlled ventilation and is therefore the recommended ventilation mode.
\end{abstract}

\section{Introduction}

As a result of major disasters, health systems have focused on the need for simultaneous medical care for a large number of victims [1-5]. The global crisis triggered by the SARS-CoV-2 pandemic created a sudden shortage of ventilators that has led to an increase in the number of deaths [6]. Triage protocols are needed for the efficient allocation of these scarce critical care resources $[7,8]$, considering that this could result in potential legal liability [9].

Since the beginning of the pandemic, several teams have focused on multiple ventilations as a possible solution to this 
huge problem. However, these efforts were soon discouraged by some of the most important scientific societies due to the limitations and potential risks of this strategy [10].

Recently, we reported the results of the evaluation, in lung-healthy pigs, of a new medical device called DuplicAR $^{\circledR}[11]$. This device was designed to enable mechanical ventilation of two subjects with a single ventilator, without cross-contamination, and allowing for independent management of peak inspiratory pressure (PIP) and positive-end expiratory pressure (PEEP).

The aims of this study are (a) to determine the efficacy of the DuplicAR ${ }^{\circledR}$ device to independently regulate PIP and PEEP in each subject, both under pressure-controlled ventilation (PCV) and volume-controlled ventilation (VCV) and (b) to determine the ventilation mode in which DuplicAR ${ }^{\circledR}$ presents the best performance and safety.

\section{Materials and Methods}

2.1. The DuplicA ${ }^{\circledR}$ Device. DuplicAR ${ }^{\circledR}$ is a novel device that allows simultaneous and independent ventilation of two subjects with only one ventilator. It is a simple adapter that is connected to the ventilator and provides independent pressurization of the system for the two subjects (Figure 1). It consists of two adapters embedded in the same device. The inspiratory part of the device connects the inspiratory port of the ventilator to each subject's inspiratory limb and has (1) valves that regulate flow and therefore tidal volume (VT) and PIP and (2) one-way valves that allow independent management of the two circuits and avoid cross-contamination. The expiratory part of the device connects to each subject's expiratory limb and to the expiratory port of the ventilator. Each expiratory limb has a PEEP controller for independent management of this variable. Cross-contamination is prevented through one-way valves and microbiological filters in each line of the circuit.

2.2. Experimental Model. The effectiveness of the DuplicAR ${ }^{\circledR}$ device for combined ventilation is studied in an in vitro experimental model (Figure 2). Two artificial lungs (test lungs), from now on called Subject A and Subject B, are connected to a single ventilator using the DuplicAR ${ }^{\circledR}$ device. Subject $A$ is considered "standard." Its attributes remain unchanged throughout the experiments. It simulates a $50 \mathrm{~kg}$ patient and is represented by a test lung with a compliance of $30 \mathrm{ml} / \mathrm{cm} \mathrm{H}_{2} \mathrm{O}$ $\left(0.6 \mathrm{ml} \mathrm{cm} \mathrm{H} \mathrm{O}^{-1} \mathrm{~kg}^{-1}\right)$. The target VT is $350 \mathrm{ml}(7 \mathrm{ml} / \mathrm{kg})$. On the other hand, Subject B is modified throughout the experiments to represent different scenarios. A VTnormalized to weight of $7 \mathrm{ml} / \mathrm{kg}$ is also targeted for this subject.

In all cases, the respiratory rate is a fixed parameter (12 ventilations per minute), which cannot be individualized for each subject. We assume that ventilation occurs in the region between the lower and upper inflection points of the pressure-volume curve. According to this, the compliance of each subject is modeled as a constant. Both subjects are presumed to be conditioned for their best lung pressurevolume curve. In clinical terms, this would mean that patients' lungs have been optimally recruited.
The experiments are performed using a Newport e360 ventilator (Newport Medical, Costa Mesa, CA) connected to the DuplicAR ${ }^{\circledR}$ system. This device is in turn connected to two portable precision test lungs with adjustable compliance and resistance (ACCU LUNG, Fluke Biomedical, Everett, WA, USA) using regular circuit tubing. Two gas flow analyzers (VT 650, Fluke Biomedical, Everett, WA, USA) are also used, each one placed between the test lung and its respective Y-piece (Figure 2).

2.3. Experimental Stages. Three experimental stages are established for the study, according to the simulated patient's weights and lung compliances:

(i) Stage 1: two identical subjects (the same weight and compliance)

(ii) Stage 2: two subjects with the same weight but different compliance

(iii) Stage 3: two subjects with different weights and compliances

At each stage, subjects $\mathrm{A}$ and $\mathrm{B}$ are connected to the ventilator using the DuplicAR ${ }^{\circledR}$ device and ventilated in PCV and VCV. The target volume established for each subject in all stages is $7 \mathrm{ml} / \mathrm{kg}$. This target VT is achieved through manipulation of the ventilator (PIP in PCV or VT in VCV) in combination with the flow controllers of the DuplicAR ${ }^{\circledR}$ device. The PEEP in the ventilator is set to $5 \mathrm{~cm} \mathrm{H}_{2} \mathrm{O}$ and maintained at that value throughout the experience. In experiment I, considered the "baseline situation," there is no difference in PEEP among subjects. A difference in PEEP is achieved through manipulation of the PEEP controller of the DuplicAR ${ }^{\circledR}$ device. The PEEP in Subject B is then successively increased to $7-10 \mathrm{~cm} \mathrm{H}_{2} \mathrm{O}$ (experiment II) and $11-14 \mathrm{~cm} \mathrm{H}_{2} \mathrm{O}$ (experiment III), while Subject A maintains $5 \mathrm{~cm} \mathrm{H}_{2} \mathrm{O}$.

The three stages are summarized in Table 1.

\section{Results}

\subsection{Stage 1. The data are shown in Tables 2 and 3.}

As evidenced in experiment I, regardless of the ventilation mode, without intervention, the driving pressure is not significantly different in both subjects $(10.5 \pm 0.45 \mathrm{~cm}$ $\mathrm{H}_{2} 0$ ), and therefore, the VT is also very similar $(354 \pm 9.36 \mathrm{ml})$.

In both ventilation modes, it is possible to increase the PEEP of Subject B without compromising its own driving pressure or that of Subject A. This is achieved in PCV by (1) increasing the PIP in the ventilator in the same amount as the increase introduced in the PEEP of Subject B and (2) restricting at the same time the PIP of Subject A through manipulation of the flow controller of the DuplicAR ${ }^{\circledR}$ device.

In VCV, as the PEEP of Subject B increases through manipulation of the PEEP controller of the device, it is necessary to adjust the flow controller of Subject A. This is mandatory as otherwise air would not enter Subject B until the system reaches the breakdown pressure generated by the 


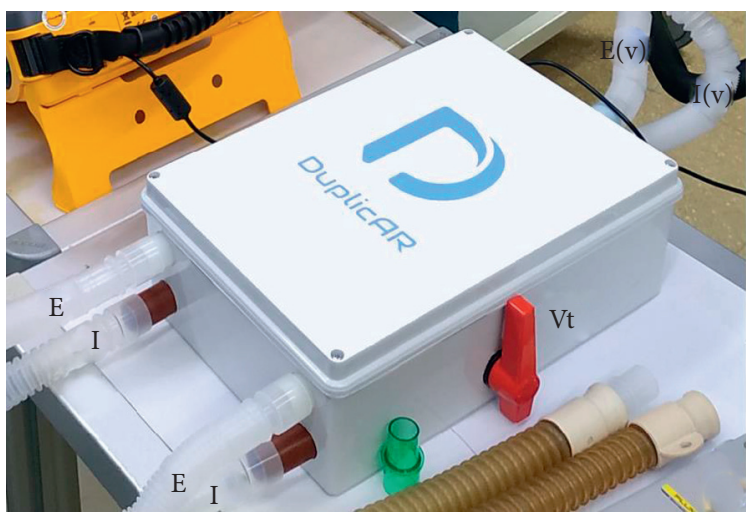

(a)

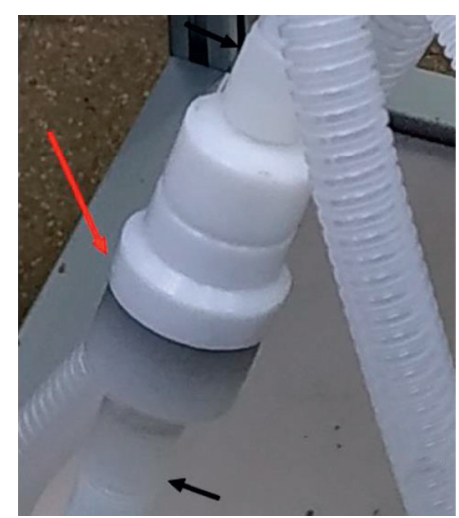

(b)

FIgure 1: The DuplicAR ${ }^{\circledR}$ device: (a) the device with its connections; (b) the PEEP valve controller. E, expiratory limb of each subject; E (v), expiratory limb connected to the ventilator; I, inspiratory limb of each subject; I (v), inspiratory limb connected to the ventilator; Vt, tidal volume/peak-pressure controller; red arrow, PEEP controller; black arrows, expiratory limb.

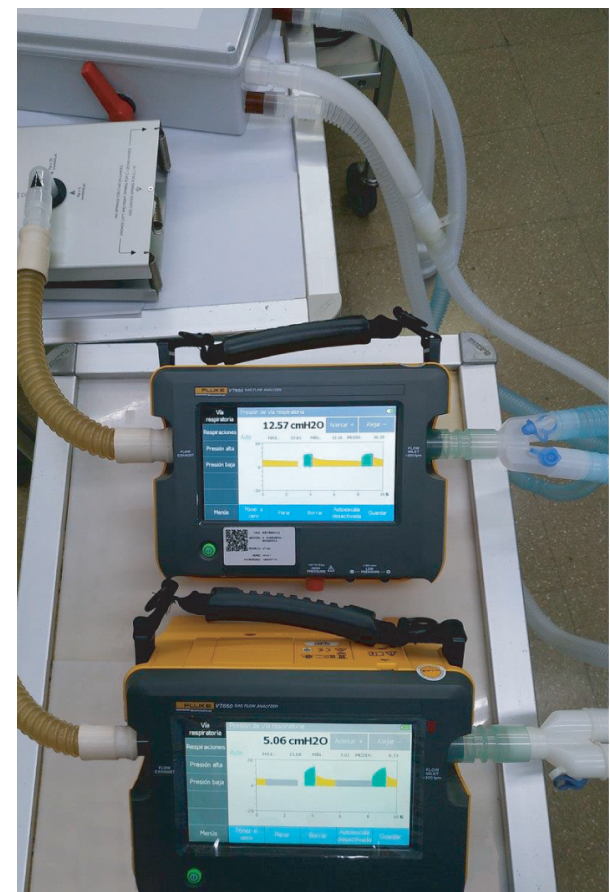

FIGURE 2: The experimental model: a ventilator connected through the DuplicAR ${ }^{\circledR}$ device to two gas flow analyzers and their respective test lungs.

PEEP valve, causing a disproportionate increase in the VT delivered to Subject A.

\subsection{Stage 2. The data are shown in Tables 4 and 5 .}

Both subjects have the same size and require the same VT $(350 \mathrm{ml})$. Since subject B has a decreased compliance compared to Subject A, its driving pressure needs to be higher:
TABLE 1: Summary of the three stages, simulating the different possible combinations of subjects' weights and lung compliances. The ventilator is configured in each mode to adequately ventilate the two subjects with a target volume of $7 \mathrm{ml} / \mathrm{kg}$. The controllers of the DuplicAR ${ }^{\circledR}$ device are manipulated to deliver asymmetric flow or different PEEP to the subjects.

\begin{tabular}{|c|c|c|c|}
\hline & Stage 1 & Stage 2 & Stage 3 \\
\hline & A & A & A \\
\hline Weight (kg) & $50 \quad 50$ & 50 & 50 \\
\hline Compliance $\left(\mathrm{ml} / \mathrm{cm} \mathrm{H}_{2} \mathrm{O}\right)$ & 30 & 30 & 30 \\
\hline Compliance $\left(\mathrm{ml} \mathrm{cm} \mathrm{H} \mathrm{O}^{-1} \mathrm{~kg}^{-1}\right)$ & 0.6 & $0.6 \quad 0.4$ & $0.6 \quad 0.35$ \\
\hline PEEP ventilator $\left(\mathrm{cm} \mathrm{H}_{2} \mathrm{O}\right)$ & 5 & 5 & 5 \\
\hline $\mathrm{I}: \mathrm{E}$ ratio & $1: 2$ & $1: 2$ & $1: 2$ \\
\hline Target volume $(\mathrm{ml} / \mathrm{kg})$ & 7 & 7 & 7 \\
\hline Total target load $(\mathrm{ml})$ & 350350 & 350350 & $350 \quad 196$ \\
\hline Peak pressure in PCV $\left(\mathrm{cm} \mathrm{H}_{2} \mathrm{O}\right)$ & 15 & 21 & 22 \\
\hline Tidal volume in VCV $(\mathrm{ml})$ & 700 & 700 & 546 \\
\hline DuplicAR flow manipulation & No No & Yes No & Yes No \\
\hline PEEP experiment $\mathrm{I}\left(\mathrm{cm} \mathrm{H} \mathrm{H}_{2} \mathrm{O}\right)$ & 5 & 5 & 5 \\
\hline PEEP experiment II $\left(\mathrm{cm} \mathrm{H}_{2} \mathrm{O}\right)$ & $5 \quad 10$ & $5 \quad 10$ & $5 \quad 10$ \\
\hline PEEP experiment III $\left(\mathrm{cm} \mathrm{H}_{2} \mathrm{O}\right)$ & 15 & 15 & 15 \\
\hline
\end{tabular}

Driving pressure Subject A : $\frac{350 \mathrm{ml}}{30 \mathrm{ml}} \mathrm{cm} \mathrm{H}_{2} \mathrm{O}^{-1}=11.7 \mathrm{~cm} \mathrm{H}_{2} \mathrm{O}$,

Driving pressure Subject B : $\frac{350 \mathrm{ml}}{20 \mathrm{ml}} \mathrm{cm} \mathrm{H}_{2} \mathrm{O}^{-1}=17.5 \mathrm{~cm} \mathrm{H}_{2} \mathrm{O}$.

To achieve this difference in each subject's driving pressure in PCV, PIP must be increased in the ventilator to deliver the adequate VT to the subject with the lowest compliance (in this case, Subject B), and afterwards, PIP in Subject A is decreased through manipulation of the respective flow controller of the DuplicAR ${ }^{\circledR}$ device.

In VCV, the VT is delivered by the ventilator to the two subjects as a whole, but its distribution is asymmetric due to 
Table 2: Stage 1 in PCV.

\begin{tabular}{lcccccc}
\hline & \multicolumn{2}{c}{ Experiment } & \multicolumn{2}{c}{ Experiment } & \multicolumn{2}{c}{ Experiment } \\
& \multicolumn{2}{c}{ I } & \multicolumn{2}{c}{ II } & \multicolumn{2}{c}{ III } \\
& A & B & A & B & A & B \\
\hline PA max $\left(\mathrm{cm} \mathrm{H}_{2} \mathrm{O}\right)$ & 16.12 & 15.92 & 16.25 & 21.78 & 16.12 & 24.61 \\
PA min $\left(\mathrm{cm} \mathrm{H}_{2} \mathrm{O}\right)$ & 5.37 & 5.11 & 4.92 & 10.35 & 4.24 & 13.41 \\
Driving $\left(\mathrm{cm} \mathrm{H}_{2} \mathrm{O}\right)$ & 10.75 & 10.81 & 11.33 & 11.43 & 11.88 & 11.2 \\
$\mathrm{C}\left(\mathrm{ml} / \mathrm{cm} \mathrm{H} \mathrm{H}_{2} \mathrm{O}\right)$ & 33.95 & 33.21 & 31.16 & 30.53 & 30.3 & 30.89 \\
$\mathrm{Vt}(\mathrm{ml})$ & 365 & 359 & 353 & 349 & 360 & 346 \\
$\mathrm{Vt} / \mathrm{kg}(\mathrm{ml} / \mathrm{kg})$ & 7.3 & 7.18 & 7.06 & 6.98 & 7.2 & 6.92 \\
\hline
\end{tabular}

TABLe 3: Stage 1 in VCV.

\begin{tabular}{lcccccc}
\hline & \multicolumn{2}{c}{ Experiment } & \multicolumn{2}{c}{ Experiment } & \multicolumn{2}{c}{ Experiment } \\
& \multicolumn{2}{c}{ I } & \multicolumn{2}{c}{ II } & \multicolumn{2}{c}{ III } \\
& A & B & A & B & A & B \\
\hline $\mathrm{PA} \mathrm{max}\left(\mathrm{cm} \mathrm{H}_{2} \mathrm{O}\right)$ & 15.19 & 15.72 & 15.64 & 22.12 & 15.62 & 24.83 \\
$\mathrm{PA} \min \left(\mathrm{cm} \mathrm{H}_{2} \mathrm{O}\right)$ & 5.36 & 5.13 & 5.33 & 10.79 & 4.52 & 13.26 \\
Driving $\left(\mathrm{cm} \mathrm{H}_{2} \mathrm{O}\right)$ & 9.83 & 10.59 & 10.31 & 11.33 & 11.1 & 11.57 \\
$\mathrm{C}\left(\mathrm{ml} / \mathrm{cm} \mathrm{H} \mathrm{H}_{2} \mathrm{O}\right)$ & 35.10 & 32.86 & 33.56 & 30.45 & 30.27 & 30.51 \\
$\mathrm{Vt}(\mathrm{ml})$ & 345 & 348 & 346 & 345 & 336 & 353 \\
$\mathrm{Vt} / \mathrm{kg}(\mathrm{ml} / \mathrm{kg})$ & 6.9 & 6.96 & 6.92 & 6.9 & 6.72 & 7.06 \\
\hline
\end{tabular}

TABle 4: Stage 2 in PCV.

\begin{tabular}{lcccccc}
\hline & \multicolumn{2}{c}{ Experiment } & \multicolumn{2}{c}{ Experiment } & \multicolumn{2}{c}{ Experiment } \\
& \multicolumn{2}{c}{ I } & \multicolumn{2}{c}{ II } & \multicolumn{2}{c}{ III } \\
& A & B & A & B & A & B \\
\hline $\mathrm{PA} \mathrm{max}\left(\mathrm{cm} \mathrm{H}_{2} \mathrm{O}\right)$ & 15.78 & 21.57 & 16.01 & 24.72 & 16 & 27.77 \\
$\mathrm{PA} \min \left(\mathrm{cm} \mathrm{H}_{2} \mathrm{O}\right)$ & 5.49 & 5.25 & 5.23 & 8.7 & 5.02 & 12.6 \\
$\mathrm{Driving}\left(\mathrm{cm} \mathrm{H}_{2} \mathrm{O}\right)$ & 10.29 & 16.32 & 10.78 & 16.02 & 10.98 & 15.17 \\
$\mathrm{C}\left(\mathrm{ml} / \mathrm{cm} \mathrm{H} \mathrm{H}_{2} \mathrm{O}\right)$ & 34.69 & 21.32 & 33.86 & 22.41 & 31.97 & 23.47 \\
$\mathrm{Vt}(\mathrm{ml})$ & 357 & 348 & 365 & 359 & 351 & 356 \\
$\mathrm{Vt} / \mathrm{kg}(\mathrm{ml} / \mathrm{kg})$ & 7.14 & 6.96 & 7.3 & 7.18 & 7.02 & 7.12 \\
\hline
\end{tabular}

TABle 5: Stage 2 in VCV.

\begin{tabular}{lcccccc}
\hline & \multicolumn{2}{c}{ Experiment } & \multicolumn{2}{c}{ Experiment } & \multicolumn{2}{c}{ Experiment } \\
& \multicolumn{2}{c}{ I } & \multicolumn{2}{c}{ II } & \multicolumn{2}{c}{ III } \\
& A & B & A & B & A & B \\
\hline PA max $\left(\mathrm{cm} \mathrm{H}_{2} \mathrm{O}\right)$ & 16.62 & 20.71 & 16.19 & 23.96 & 16 & 27.71 \\
PA min $\left(\mathrm{cm} \mathrm{H}_{2} \mathrm{O}\right)$ & 5.46 & 5.22 & 5.11 & 8.54 & 5 & 12.33 \\
Driving $\left(\mathrm{cm} \mathrm{H}_{2} \mathrm{O}\right)$ & 11.16 & 15.49 & 11.08 & 15.42 & 11 & 15.38 \\
$\mathrm{C}\left(\mathrm{ml} / \mathrm{cm} \mathrm{H} \mathrm{H}_{2} \mathrm{O}\right)$ & 31.45 & 21.82 & 30.51 & 22.31 & 30.91 & 21.98 \\
$\mathrm{Vt}(\mathrm{ml})$ & 351 & 338 & 338 & 344 & 340 & 338 \\
$\mathrm{Vt} / \mathrm{kg}(\mathrm{ml} / \mathrm{kg})$ & 7.02 & 6.76 & 6.76 & 6.88 & 6.8 & 6.76 \\
\hline
\end{tabular}

the differences in subjects' characteristics. The adequate VT for each subject needs to be regulated through manipulation of the flow controller of the DuplicAR ${ }^{\circledR}$ device of the subject with greater compliance. In this way, with a single ventilator configuration, different driving pressures are established.

In both ventilation modes, it is possible to modify PEEP of a subject without compromising its driving pressure or modifying the other subject's parameters. In each of the three experiments, the driving pressures are preserved. In $\mathrm{PCV}$, this is accomplished by increasing PIP in the ventilator setting to maintain the driving pressure of the subject with increased PEEP (Subject B). Accurate driving pressure in Subject $A$ is modulated by the flow controller of the DuplicAR ${ }^{\circledR}$ device, thus preventing an excessive PIP (Figure 2). In VCV, the total VT is set. When the PEEP of Subject $\mathrm{B}$ is selectively increased, the flow controller of Subject A is adjusted to achieve an adequate distribution of the total VT.

\subsection{Stage 3. The data are shown in Tables 6 and 7.}

In this situation, the two subjects have important disparities in terms of weight and lung compliance. Subject A is a simulated patient weighing $50 \mathrm{~kg}$ with a lung compliance of $30 \mathrm{ml} / \mathrm{cm} \mathrm{H}_{2} \mathrm{O}$, while Subject B simulates a patient weighing $28 \mathrm{~kg}$ with a lung compliance of $10 \mathrm{ml} / \mathrm{cm} \mathrm{H}_{2} \mathrm{O}$. The driving pressures that each subject requires are

$$
\begin{aligned}
& \text { Driving pressure of Subject A: } \frac{350 \mathrm{ml}}{30 \mathrm{ml}} \mathrm{cm} \mathrm{H}_{2} \mathrm{O}^{-1}=11.7 \mathrm{~cm} \mathrm{H}_{2} \mathrm{O} \text {, } \\
& \text { Driving pressure of Subject B: } \frac{196 \mathrm{ml}}{10 \mathrm{ml}} \mathrm{cm} \mathrm{H}_{2} \mathrm{O}^{-1}=19.6 \mathrm{~cm} \mathrm{H}_{2} \mathrm{O} \text {. }
\end{aligned}
$$

In order to achieve this difference in each subject's driving pressure in PCV, PIP in the ventilator must first be configured to ensure ventilation to the subject with the lowest compliance (in this case, Subject B, requiring a PIP of $24 \mathrm{~cm} \mathrm{H}_{2} \mathrm{O}$ ). Afterwards, PIP in Subject $\mathrm{A}$ is decreased through manipulation of the respective flow controller of the

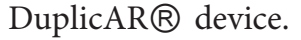

In VCV, the different driving pressures of the two subjects are achieved by setting a total VT in the ventilator and managing its distribution among subjects with the flow controllers of the DuplicAR ${ }^{\circledR}$ device, as in Stage 2.

The PEEP is also managed independently for each subject in both ventilation modes. As in Stage 2, in PCV, the driving pressures are preserved by increasing PIP of the ventilator to maintain the driving pressure of the subject with an increased PEEP (Subject B) and decreasing PIP of the other subjects through manipulation of the respective flow controller of the DuplicAR ${ }^{\circledR}$ device. In VCV, the total VT configured in the ventilator is unequally distributed to meet each subject's requirements. Since PEEP of Subject B increases, the flow controller of Subject A needs to be adjusted to achieve an adequate VT.

\section{Discussion}

Since the first cases of COVID-19 were reported in December 2019 in Wuhan as a cluster of patients with pneumonia, the disease rapidly disseminated worldwide. In a few months, some of the more robust healthcare systems in the world collapsed, as it was impossible to meet the needs of so many critically ill patients simultaneously. By the end of 2020 , more than 80 million people had suffered from the disease and almost 2 million had died.

From the beginning of the pandemic, the shortage of mechanical ventilators was at the center of the scene. People died because resource constraints limited the availability of ventilatory support $[6,12]$. On March 24, 2020, Dr. Jeremy 
TABle 6: Stage 3 in PCV.

\begin{tabular}{|c|c|c|c|c|c|c|}
\hline & \multicolumn{2}{|c|}{ Experiment I } & \multicolumn{2}{|c|}{$\begin{array}{l}\text { Experiment } \\
\text { II }\end{array}$} & \multicolumn{2}{|c|}{$\begin{array}{c}\text { Experiment } \\
\text { III }\end{array}$} \\
\hline & A & B & A & B & A & B \\
\hline $\mathrm{PA} \max \left(\mathrm{cm} \mathrm{H} \mathrm{H}_{2} \mathrm{O}\right)$ & 16.15 & 23.7 & 16.09 & 28.92 & 16.84 & 34.1 \\
\hline $\mathrm{PA} \min \left(\mathrm{cm} \mathrm{H} \mathrm{H}_{2} \mathrm{O}\right)$ & 5.44 & 5.16 & 5.03 & 7.99 & 5 & 11.3 \\
\hline Driving $\left(\mathrm{cm} \mathrm{H}_{2} \mathrm{O}\right)$ & 10.71 & 18.54 & 11.06 & 20.93 & 11.84 & 22.8 \\
\hline $\mathrm{C}\left(\mathrm{ml} / \mathrm{cm} \mathrm{H} \mathrm{H}_{2} \mathrm{O}\right)$ & 35.57 & 10.41 & 31.92 & 9.32 & 32.60 & 9.21 \\
\hline $\mathrm{Vt}(\mathrm{ml})$ & 381 & 193 & 353 & 195 & 386 & 210 \\
\hline $\mathrm{Vt} / \mathrm{kg}(\mathrm{ml} / \mathrm{kg})$ & 7.62 & 6.89 & 7.06 & 6.96 & 7.72 & 7.5 \\
\hline
\end{tabular}

Table 7: Stage 3 in VCV.

\begin{tabular}{lcccccc}
\hline & \multicolumn{2}{c}{ Experiment } & \multicolumn{2}{c}{ Experiment } & \multicolumn{2}{c}{ Experiment } \\
& \multicolumn{2}{c}{ I } & \multicolumn{2}{c}{ II } & \multicolumn{2}{c}{ III } \\
& A & B & A & B & A & B \\
\hline PA max $\left(\mathrm{cm} \mathrm{H}_{2} \mathrm{O}\right)$ & 16.33 & 23.26 & 17.02 & 27.03 & 16.95 & 33.61 \\
PA min $\left(\mathrm{cm} \mathrm{H}_{2} \mathrm{O}\right)$ & 5.42 & 5.16 & 5.15 & 7.51 & 4.98 & 11.46 \\
Driving $\left(\mathrm{cm} \mathrm{H}_{2} \mathrm{O}\right)$ & 10.91 & 18.1 & 11.87 & 19.52 & 11.97 & 22.15 \\
$\mathrm{C}\left(\mathrm{ml} / \mathrm{cm} \mathrm{H}_{2} \mathrm{O}\right)$ & 30.25 & 10.77 & 30.75 & 9.89 & 29.99 & 9.48 \\
$\mathrm{Vt}(\mathrm{ml})$ & 330 & 195 & 365 & 193 & 359 & 210 \\
$\mathrm{Vt} / \mathrm{kg}(\mathrm{ml} / \mathrm{kg})$ & 6.6 & 6.96 & 7.3 & 6.89 & 7.18 & 7.5 \\
\hline
\end{tabular}

Beitler, Richard Branson, and colleagues from the Columbia University College of Physicians and Surgeons and the New York-Presbyterian Hospital published a ventilator-sharing protocol for dual-patient ventilation with a single mechanical ventilator for use during critical ventilator shortage [13]. This was just one of the multiple responses from the worldwide healthcare community to the crisis.

However, two days later, on March 26, with 462,680 cases diagnosed worldwide, the Society of Critical Care Medicine (SCCM), the American Association for Respiratory Care (AARC), the American Society of Anesthesiologists (ASA), the Anesthesia Patient Safety Foundation (APSF), the American Association of Critical-Care Nurses (AACN), and the American College of Chest Physicians (CHEST) issued a joint statement on the concept of placing multiple patients on a single mechanical ventilator [10]. The central message was that sharing mechanical ventilators should not be attempted because it could not be performed safely with equipment available at that time. The document was concise but robust and addressed all issues related to multiple ventilations, as it was being performed at the moment.

At the same time, with the aim of overcoming these issues, our team created a new medical device (patent application submitted), called DuplicAR ${ }^{\circledR}$. This device allows for independent ventilation of two subjects with only one ventilator. In this way, the concept of "combined ventilation" (different from "multiple" or "shared" ventilation) was born. In it, mutual interactions between the two subjects connected to the same ventilator are considered, and individual needs are attended to ventilate them adequately. The results of the use of this device in a lung-healthy animal model were published recently [11].
In the present work, we demonstrate in an in vitro model that most of the problems outlined by the joint statement can be overcome with this new medical device.

One of the strongest arguments exposed against multiple ventilations was that VT (or PIP, according to the mode of mechanical ventilation) and PEEP (which is of critical importance in COVID-19 patients) would be impossible to manage. Here, we demonstrate that these variables can be managed independently to ventilate the two subjects adequately, even if they have different weights and/or lung compliances and/or PEEP requirements. This is achieved by adjusting the total VT for both subjects (or the highest PIP needed) and basal PEEP on the ventilator and manipulating the DuplicAR ${ }^{\circledR}$ controllers to decrease VT or PIP in the subject that needs less and increase PEEP in the subject that needs more.

While we show that the ventilatory goals can be achieved both in PCV and VCV, VCV has major disadvantages compared to PCV. Although the total VT for both subjects in VCV can be distributed asymmetrically between them (using DuplicAR ${ }^{\circledR}$ to overcome the problem of volumes going to the most compliant lung), this mode introduces the possibility of deleterious interactions between subjects. For example, if a subject's endotracheal tube gets kinked, the other subject will receive a dangerously large VT. This happens because sudden changes in resistance or compliance in one subject directly impact on the other. A similar phenomenon is observed when increasing PEEP selectively in one subject. In VCV, the other subject receives a greater $\mathrm{VT}$, since it is necessary that the inspiratory tubing reaches greater pressure to allow the volume to be delivered to the subject with greater PEEP. This is accomplished at the expense of increasing volume on the subject with no modification of the PEEP.

All these problems can be overcome using continuous mandatory PCV, the mode of ventilation recommended for DuplicAR ${ }^{\circledR}$, and adding profound sedation and paralyzation of both patients. Despite the fact that a guaranteed VT cannot be delivered to any patient (not different from having only one patient on PCV), the ability to control and limit the driving pressure of each individual regardless of weight, airway resistance, and lung compliance may allow this strategy to be reasonably lung protective. Besides, an increase in one subject's PEEP (without modifying PIP on the ventilator) only affects the subject in whom the PEEP is modified, by decreasing the driving pressure and therefore the VT. Another advantage of PCV is that sudden changes in one subject (i.e., dynamic compliance variability or endotracheal tube obstruction) do not affect the pressurization of the system and therefore have no consequences on the other subject [13]. Deleterious interactions between patients are then mostly avoided using this mode. For example, if Subject A's endotracheal tube gets kinked, Subject A will receive a reduced VT, but this will have no impact on Subject B. Finally, PCV spontaneously compensates for the compliance added to the system by the tubing, which in combined ventilation is expected to contain twice the volume compared to single (conventional) ventilation. In VCV, in 
contrast, this must be manually compensated by adding an extra volume to the total VT delivered by the ventilator.

The individualized management described above can easily be maintained with DuplicAR ${ }^{\circledR}$ over time, as the PIP and PEEP can be adjusted to the subjects' requirements at any time. Patients could deteriorate and recover at different rates, and the distribution of gas to each patient would be monitored and adjusted to each patient's needs in a continuous fashion. It is important to note that this adjustment has to be performed considering that the respiratory rate will be the same for both subjects.

Finally, there are two other major concerns highlighted by the joint statement, which DuplicAR ${ }^{\circledR}$ can adequately address. The first is related to monitoring and setting alarms during multiple ventilations. In the recently published animal model, we monitor the airway pressures in each animal using a regular pressure transducer connected between the Y-piece and a multiparameter monitor [11]. We are currently working on an advanced prototype with alarms, direct measurement in real time of all the variables of each subject and electronic closed-loop control of PIP and PEEP in each individual through a human-machine interface. This advanced prototype could be complemented with the use of capnography added to each circuit, as recently described by Korsós and collaborators [14]. Although the strategy for flow manipulation in our device is not the same as the one described by these authors (we manipulate the resistance of the individual circuits in the inspiratory lines, not at the level of the endotracheal tube), this simple and goal-oriented method could provide additional information to ensure the adequacy of ventilation to the two subjects during this lifesaving intervention.

The second concern outlined by the joint statement was that patients could share gas between circuits. Pendelluft was considered possible between patients, leading to both crossinfection and overdistension. However, this is avoided with the DuplicAR ${ }^{\circledR}$ device, which has filters and one-way valves that isolate patient circuits from each other.

4.1. Limitations. The present study has limitations. The test lungs used in this in vitro study have constant compliance. In clinical practice, this would imply that regardless of PEEP and PIP reached, the relationship between volume differential and pressure differential would behave as a constant. In real mechanical ventilation scenarios (and particularly in patients with lung disease), this relationship between volume and pressure may not be linear. In these cases, the VT would be delivered at pressure values close to the "upper inflection point," and therefore, lung compliance would progressively decrease.

In addition, the objective of this experimental in vitro model is to represent, in a reductionist way, the interactions between variables in a combined ventilation scenario. This model does not take into account other aspects that should be considered in clinical practice, such as the hemodynamic status, the quality of gas exchange, and the possibility of inadvertent spontaneous ventilation in patients under shared ventilation.
Finally, it is important to note that this device has not yet been tested in either an animal model with severe acute respiratory distress syndrome or in humans, and its use should only be considered as a life-saving bridge alternative to palliate the consequences of the sudden shortage of ventilators during catastrophic events.

\section{Conclusions}

DuplicAR ${ }^{\circledR}$ is an effective tool to manage PIP and PEEP independently in two subjects connected to a single ventilator. The driving pressures can be adjusted to meet the requirements of the two subjects, even if they have different weights, lung compliances, and/or PEEP requirements. DuplicAR ${ }^{\circledR}$ can achieve the ventilatory goals both in PCV and VCV. However, it performs better in continuous mandatory PCV, as the changes experienced in the variables of one subject do not modify the other one. PCV also compensates the compliance changes generated by the additional tubing required in combined ventilation. This new medical device may then become a useful tool to face the shortage of mechanical ventilators during health crises.

\section{Data Availability}

The data used to support the findings of this study are included within the article.

\section{Conflicts of Interest}

Lugones I is the trademark holder and the author of the patent application. All other authors declare that they have no conflicts of interest.

\section{Authors' Contributions}

All authors contributed to literature search, data collection, study design, analysis of data, manuscript preparation, and review of manuscript.

\section{Acknowledgments}

Ignacio Lugones would like to thank Luciano Gentile and Patricia Crego from the Favaloro Foundation University Hospital, Argentina, for supplying equipment to carry out the experiments. This author also thanks Juan José Díaz and Nicolás Campagne from ETYC S.A. for providing technical assistance during the study.

\section{References}

[1] D. D. Sommer, J. A. Fisher, V. Ramcharan, S Marshall, and D. M. Vidic, "Improvised automatic lung ventilation for unanticipated emergencies," Critical Care Medicine, vol. 22, no. 4, pp. 705-709, 1994.

[2] M. D. Christian, A. V. Devereaux, J. R. Dichter, L. Rubinson, and N. Kissoon, "Introduction and executive summary," Chest, vol. 146, no. 4, pp. 8S-34S, 2014.

[3] J. A. Cordova-Villalobos, A. E. Macias, M. Hernandez-Avila et al., "The 2009 pandemic in Mexico: experience and lessons regarding national preparedness policies for seasonal and 
epidemic influenza," Gac Med Mex, vol. 153, pp. 102-110, 2017.

[4] E. L. Daugherty Biddison, R. Faden, H. S. Gwon et al., "Too many patients. A framework to guide statewide allocation of scarce mechanical ventilation during disasters," Chest, vol. 155, no. 4, pp. 848-854, 2019.

[5] E. J. Emanuel, G. Persad, R. Upshur et al., "Fair allocation of scarce medical resources in the time of covid-19," The New England Journal of Medicine, vol. 382, no. 21, pp. 2049-2055, 2020.

[6] M. L. Ranney, V. Griffeth, and A. K. Jha, "Critical supply shortage-the need for ventilators and personal protective equipment during the COVID 19 pandemic," N Engl J Med, vol. 382 , p. $18,2020$.

[7] R. C. Maves, J. Downar, J. R. Dichter et al., "Triage of scarce critical care resources in COVID-19 an implementation guide for regional allocation," Chest, vol. 158, no. 1, pp. 212-225, 2020.

[8] J. Savulescu, J. Cameron, and D. Wilkinson, "Equality or utility? Ethics and law of rationing ventilators," British Journal of Anaesthesia, vol. 125, no. 1, pp. 10-15, 2020.

[9] I. G. Cohen, A. M. Crespo, and D. B. White, "Potential legal liability for withdrawing or withholding ventilators during COVID-19," Jama, vol. 323, no. 19, pp. 1901-1902, 2020.

[10] The Society of Critical Care Medicine (SCCM), American Association for Respiratory Care (AARC), American Society of Anesthesiologists (ASA), Anesthesia Patient Safety Foundation (APSF), American Association of Critical-Care Nurses (AACN), and American College of chest Physicians (CHEST), Joint Statement on Multiple Patients per Ventilator SCCM, AARC, ASA, APSF, AACN, and Chest Share Unified Message, The Society of Critical Care Medicine (SCCM), Orlando, FL, USA, 2020.

[11] I. Lugones, R. Orofino Giambastiani, O Robledo et al., "A new medical device to provide independent ventilation to two subjects using a single ventilator: evaluation in lung-healthy pigs," Anesthesiology Research and Practice, vol. 2020, Article ID 8866806, 6 pages, 2020.

[12] L. Rosembaum, "Facing covid-19 in Italy-ethics, logistics, and therapeutics on the epidemic's front line," The New England Journal of Medicine, vol. 382, pp. 1873-1875, 2020.

[13] J. R. Beitler, R. Kallet, R Kacmarek et al., "Ventilator sharing protocol: dual-patient ventilation with a single mechanical ventilator for use during critical ventilator shortages," 2020, https:// www.gnyha.org/news/working-protocol-for-supportingtwo-patie nts-with-a-single-ventilator.

[14] A. Korsós, F. Peták, R. Südy, Á Schranc, G. H. Fodor, and B. Babik, "Use of capnography to verify emergency ventilator sharing in the COVID-19 era," Respiratory Physiology \& Neurobiology, vol. 285, Article ID 103611, 2020. 